\title{
Bolaño, Borges y la cultura de fin de siglo. Una lectura de La literatura nazi en América y Estrella distante
}

\author{
Guadalupe Silva ${ }^{1}$
}

Resumen. Este artículo indaga la apropiación literaria de Borges por parte de Roberto Bolaño en dos novelas, La literatura nazi en América y Estrella distante, ambas de 1996. Si bien es conocida la orientación borgeana de estos libros de Bolaño -en especial del primero-, el aporte de este ensayo consiste en contextualizar dicha apropiación en el marco de la cultura de finales del siglo XX, y en explorar un aspecto de la obra de Borges poco atendido por la crítica de Bolaño: su faceta antifascista. A través del análisis comparado de estas novelas con el cuento de Borges "Deustches Requiem" (1946), el artículo se propone iluminar un aspecto relevante del proyecto narrativo de Bolaño.

Palabras clave: Borges; Bolaño; novela; metaficción; apropiación.

[en] Bolaño, Borges and the Culture of the End of the Century. A Reading of La liteartura nazi en América and Estrella distante

\begin{abstract}
This article investigates the literary appropriation of Borges by Roberto Bolaño in two novels, La liteartura nazi en América and Estrella distante, both from 1996. While the borgean orientation of these Bolaño books -especially the first one- is well known, the contribution of this essay is to contextualize this appropriation within the framework of the culture of the late twentieth century, and in exploring an aspect of Borges' work little attended by Bolaño's critics: his antifascist facet. Through the comparison of these novels with the story by Borges "Deustches Requiem" (1946), the article aims to illuminate a relevant aspect of Bolaño's narrative project.
\end{abstract}

Keywords: Borges; Bolaño; novel; metafiction; appropriation.

Sumario. 1. Borges fin de siglo. 2. Bolaño y la ficción borgeana. 3. El factor nazi. 4. Espejo del mal. 5. El Borges de Bolaño.

Cómo citar: Silva, G. (2020) Bolaño, Borges y la cultura de fin de siglo. Una lectura de La literatura nazi en América y Estrella distante, en Anales de Literatua Hispanoamericana 49, 79-88.

En este trabajo retomaré un tópico de la crítica que considero requiere algo más de atención. Me refiero a la marcada presencia de Borges en las dos novelas con las que Roberto Bolaño inició su etapa consagratoria como narrador, La literatura nazi en América y Estrella distante, ambas de $1996 .^{2}$ Varios análisis destacaron la impronta borgeana de estas novelas, particularmente de la primera, a la que se puso en relación con el género de las biografías infames. ${ }^{3}$ Pero se prestó menos atención a las condiciones de apropiación de la obra de Borges, o a los componentes ideológicos de esa apropiación. Me interesa volver sobre este asunto, en particular para sugerir una hipótesis sobre el papel que la lectura y el explícito homenaje a Borges podrían haber jugado en la configuración de una política y una ética de la literatura a mediados de los años noventa.

Para esto, primero pasaré revista a algunas coordenadas del "Borges fin de siglo", el Borges posestructuralista que se volvió moneda corriente entre su desaparición física en 1986 y el centenario de su nacimiento en 1999/2000. Luego voy a comentar vínculos posibles entre ese Borges fin de siglo y el primer

\footnotetext{
${ }^{1}$ Instituto de Literatura Hispanoamericana, Facultad de Filosofía y Letras, Universidad de Buenos Aires-CONICET. Buenos Aires. Argentina. Email: titillatio@gmail.com

Este trabajo es parte del Proyecto de Investigación Plurianual "La legitimación del escritor moderno en América Latina y Europa. Polémicas, operaciones, representaciones" (CONICET /UBA).

2 A lo largo de este artículo La literatura nazi en América será citada como "LLNA" y Estrella distante como "ED".

${ }^{3}$ Manzoni (2003 a y b), Walker (2013; 2014), Perrilli (2014), Aguilar (2015), Crusat (2016), Pauls (2015).
} 
Bolaño, que accede a la fama con la publicación de estos dos libros en 1996.

\section{Borges fin de siglo}

Entre fines de los setenta y los últimos años del siglo, la discusión sobre la condición posmoderna se extendió por el mundo con posicionamientos a favor y en contra. La discusión representó un intento de establecer un nuevo paradigma cultural para la época, en respuesta a lo que se consideró como una modernidad caduca. La cuestión posmoderna estuvo siempre compuesta tanto de elementos teórico-críticos como de principios programáticos. El tema es complejo y tiene muchas aristas, matices y derivaciones, que no busco recuperar aquí. Sólo pretendo evocar el clima de aquellos años en los que entraron en circulación categorías y valores que fueron contrapuestos a las totalidades, los grandes relatos, los ideales de tiempo nuevo y la voluntad de originalidad. Contra esto se reivindicaron la ficcionalidad del mundo, el simulacro, el principio de fragmentación, la distancia irónica, la inestabilidad semántica, incluso la productividad de la copia y el apócrifo. ${ }^{4}$

Al igual que otros escritores, Borges, figura central del canon argentino contemporáneo, fue revisitado en ese período como ejemplo posible de este nuevo paradigma cultural. Especialmente en tanto podía ser visto, incluso a su pesar, como un escritor postestructuralista avant la lettre. Numerosos rasgos de su obra parecían corresponderse sin esfuerzo con categorías teóricas postestructuralistas. Por citar algunas: la crítica del yo, la tendencia fragmentaria, la distancia irónica, el posicionamiento en las orillas, el aspecto metanarrativo, la intertextualidad, el coqueteo con el plagio y las atribuciones erróneas. ${ }^{5}$

La obra de Borges ya había empezado a ser revisada con esta perspectiva antes de los ochenta, en el contexto de su internacionalización. Baste mencionar los nombres de Paul de Man, Foucault y Derrida en los sesenta ${ }^{6}$ En la tradición argentina, los primeros signos de una relectura de Borges en el sentido de lo que François Cusset llamó "French Theory", deben buscarse en Las letras de Borges, el texto que Silvia Molloy escribió a fines de los setenta, y tal vez también en las agudas aproximaciones de Pezzoni recogidas en El texto y sus voces (1986). Con el retorno democrático y la refundación de la teoría literaria en la UBA, Borges y la "nueva crítica" acabaron de consolidar su unión discursiva. Esto puede verse en las clases de Pezzoni de los años ochenta, o en un libro de los noventa como el de Beatriz Sarlo Borges, un escritor en las orillas (1995), publicado un año después de Escenas de la vida posmoderna.

Pero me quiero detener en un libro que está a este lado del arco que se inicia con los trabajos de Molloy y Pezzoni. El factor Borges, de Alan Pauls, ofrece la caracterización más accesible del Borges fin de siglo al que me estoy refiriendo. El libro, coeditado con Nicolás Helft en el año 2000, como celebración del centenario del nacimiento del autor, tiene un lugar bisagra, deliberadamente buscado, entre los siglos y entre los lectores. La prosa de Pauls, aguda pero libre de jerga teórica, ensaya la relectura de Borges a través de la elaboración interpretativa de su poética. Sus temas y perspectivas están claramente atravesados por los efectos del postestructuralismo en la crítica argentina. Una serie de rasgos que Pauls atribuye al "código genético" de Borges están asociados claramente con la nueva axiología: lo parasitario, lo menor, la literatura de segundo grado, la preferencia del archivo y la biblioteca, la práctica de la erudición y la lectura como prácticas activas, el peculiar uso del género de la vida... En su propia definición, El factor Borges es un "ensayo de lectura" que revisa los textos en busca de "esa propiedad, ese elemento singular, esa molécula que hace que Borges sea Borges y que, 'liberada' gracias a la lectura, la traducción, las múltiples instancias de reproducción que desde hace más o menos cuarenta años vienen encarnizándose con Borges y su obra, hace también que el mundo sea cada día un poco más borgeano" (Pauls 2000: 7-8). Esta última línea en la que Pauls habla de un mundo "cada día un poco más borgeano", revela hasta qué punto Pauls encuentra en

\footnotetext{
${ }^{4}$ Desde luego, estas son afirmaciones generales. No pretendo sugerir que el rótulo "posmoderno" exprese una única posición ante al mundo ni una uniformidad histórica. De hecho, numerosos experimentos que se condujeron en ese clima cultural terminaron engendrando nuevas, diversas y potentes líneas de pensamiento y reflexión. Pero es la existencia operativa de ese clima cultural lo que subrayo evocando la categoría "posmoderno".

${ }^{5}$ Como se propuso demostrar el libro de José Cuesta Abad, Ficciones de una crisis (1995). Cuesta Abad define como propósito de su libro establecer "relaciones analógicas, parentescos culturales y asociaciones ideológicas entre el pensamiento borgeano y los contenidos filosóficos o teóricos del postestructuralismo" (1995: 18).

${ }^{6}$ Al Borges traducido al inglés, lo había estudiado Paul de Man en 1964 (“A Modern Master”); al Borges en francés lo citaron Foucault (Las palabras y las cosas, 1966) y Derrida (La farmacia de Platón, como ilustración de sus proposiciones programáticas a fines de esa misma década.
} 
ese "factor" una clave de la contemporaneidad estética.

A su vez, Pauls indagó la relación entre Bolaño y Borges con una agudeza notable en una conferencia más reciente, que puede consultarse en línea, "Borges y Bolaño, una conversación" (2015). Allí señala cuatro puntos en los que la poética bolañana converge con la del maestro argentino: 1) la figura del "gran lector" o la lectura como una "práctica activa", 2) el "enciclopedismo internacional", 3) la "fascinación por el apócrifo" como una forma de oposición "a todas las ideologías de la autenticidad que están absolutamente ligadas al imaginario del boom latinoamericano", y 4) el género "vida de escritor" como "forma literaria de resurrección de experiencias perdidas". Como se ve, estos cuatro aspectos se corresponden con rasgos centrales del "factor Borges" y son a su vez componentes claves en el trazado de una línea divisoria que separa a la literatura contemporánea de la generación del boom.

Pauls es compañero generacional de Bolaño, y como él, inició su proyecto de escritor en diálogo con la obra de Borges. De hecho, es reveladora la coincidencia de su diagnóstico sobre un mundo "cada día más borgeano", con el diagnóstico que enuncia Bolaño en la nota introductoria de Estrella distante, donde también se refiere al presente como un tiempo habitado por el "fantasma cada día más vivo de Pierre Menard" (ED: 11). Si hago hincapié en el ámbito borgista argentino, y especialmente en Pauls, es porque Bolaño leyó con particular interés la literatura de este país, a la que situó, a través de Borges, en el centro del canon latinoamericano. ${ }^{8}$

\section{Bolaño y la ficción borgeana}

Bolaño dejó algunas de sus propias opiniones sobre Borges en las conferencias y artículos periodísticos que fueron recolectados en el libro Entre paréntesis (2004). Comparados con un libro como el de Pauls, hay que decir que sus ensayos resultan bastante menos sutiles y están en general dirigidos a la polémica. En todo caso, ciertamente nos indican que Bolaño consideraba a Borges como el mayor escritor latinoamericano del siglo veinte. Las implicancias más importantes de esta admiración, sin embargo, no deben buscarse allí, en los ensayos de Bolaño, sino en su obra de ficción, y especialmente en esas dos novelas con las que logró entrar, después de muchos intentos, en el gran mercado editorial: La literatura nazi en América y Estrella distante, publicadas por Seix Barral y Anagrama, respectivamente.

La literatura nazi en América ofrece una colección de biografías apócrifas y humorísticas de escritores y artistas de segundo orden que guardan algún tipo de relación ideológica, no siempre explícita, con temas y principios del fascismo y el nazismo. La impronta borgeana del texto se hace manifiesta en su serialización de biografías y en el hecho de tomar como hilo conector la idea de crimen e infamia, rasgos que remiten directamente a Historia universal de la infamia (1935), aunque también a otro libro de la misma estirpe schwobiana, La sinagoga de los iconoclastas de Rodolfo Wilcock (1972) y a otros textos de Borges, como la serie de biografías publicadas en la revista El Hogar entre 1935 y 1958. ${ }^{9}$ La galería de "infames" de $L a$ literatura nazi en América se caracteriza por el intento de agotar todas las posibles variantes y paradojas de la relación entre el arte y la política, las vanguardias y los programas totalitarios, la cultura letrada y las barbaries del siglo xx, a través de este inventario delirante de biografías caricaturescas. Esto ya supone un complejo movimiento de lectura y apropiación, pero también de reinvención de fórmulas borgeanas. Bolaño complejiza su diálogo con Borges al combinar la narración de vidas, la parodia y la reescritura (Crusat 2014), con el artificio de construir un texto apócrifo, tal como hizo Borges en "Pierre Menard, autor del Quijote",

7 La selectiva bibliografía de El factor Borges es coherente con esta perspectiva. Bajo el título "Otras publicaciones", leemos los nombres de Foucault, Link, Ludmer, Molloy, Piglia y Sarlo. Aunque llama la atención la ausencia de Pezzoni, todos ellos componen una suerte de mapa doctrinal calibrado con el fin de siglo. Pero más elocuente todavía que estos nombres previsibles, es el de Ramón Doll. Como sabemos, Doll pertenece a la tradición del "Antiborges": recordemos que lo había definido como "yermo intelectual sin jugos vitales ni aliento" (Antiborges 35). Pero Pauls invocaba a Doll para revertirlo: si Doll había denunciado el "parasitismo literario" de Borges en 1933, Pauls celebraba en el 2000 que hubiera identificado esa cualidad. Para Pauls, Borges es un sujeto lúcido, una suerte de héroe, que abraza el valor de la copia, del parasitismo literario, sin dudarlo. "Es muy probable que Borges, contra toda expectativa de Doll, no la haya desaprobado. Con la astucia y el sentido de la economía de los grandes inadaptados, que reciclan los golpes del enemigo para fortalecer los propios, Borges no rechaza la condena de Doll, sino que la convierte -la revierte- en un programa artístico propio" (2000: 104).

${ }^{8}$ Borges, escribió Bolaño (2013a: 23), es “probablemente el mayor escritor que haya nacido en Latinoamérica”. En referencia a Ficciones y El Aleph, Bolaño afirmó que "probablemente son los dos mejores libros de relatos escritos en español en el siglo XX" (2013a: 291). También con Pauls se mostró elogioso: "Es usted uno de los mejores escritores latinoamericanos vivos", le dice en un ensayo (2013b: 209). Uno de los últimos textos donde Bolaño reafirma la primacía de Borges, "Los mitos de Cthulhu" (2003), está dedicado a Pauls.

${ }^{9}$ La sinagoga degli iconoclasti fue publicado originalmente en Milán por editorial Adelphi. La serie de biografías de Borges pueden verse en la recopilación: Borges en El Hogar (1935-1958). Buenos Aires: Emecé, 2000. A la lista de posibles referencias borgeanas, Alan Pauls (2015) agrega las Crónicas de Bustos Domeq (Buenos Aires: Losada, 1967), escritas en colaboración con Adolfo Bioy Casares. 
cuento al que no casualmente se hace referencia en la nota introductoria de Estrella distante. En La literatura nazi en América, Bolaño profundiza este recurso extendiendo el apócrifo a la dimensión de la novela. De manera que no solo recicla un artilugio borgeano, sino que obliga al lector a descubrir en qué momento ese gran apócrifo de 237 páginas (en edición de Anagrama) deja de ser una falsa enciclopedia para constituirse en una narración. Se diría que Bolaño extrema ese recurso de Borges y a la vez lo lleva en una dirección distinta, introduciendo en la última parte del libro un sorpresivo giro ficcional que revela el carácter novelístico del texto. La pregunta es si este redireccionamiento constituye el límite de la impronta borgeana en La literatura nazi en América, o si hay otros aspectos de Borges que también repercuten en él, así como en la secuela de este libro, Estrella distante.

El "borgismo" como acción corrosiva, basada en la ironía, el simulacro, la reescritura y la toma de distancia respecto de la propia práctica literaria, es solo el primer movimiento de una operación más compleja. El tipo de apropiación por parte de Bolaño en relación con Borges solo se entiende si se considera el segundo movimiento. Esta segunda instancia de apropiación se pone de manifiesto en el cierre de $L a$ literatura nazi en América, justamente el punto que luego se retoma para ser amplificado en la novela posterior, Estrella distante, la cual, a su vez, da pie a toda la saga de Arturo Belano. El movimiento consiste en repolitizar una obra frecuentemente considerada como literatura pura indiferente al contexto, es decir, en reactivar el potencial de las ficciones borgeanas como crítica ideológica. Como estudió Annick Louis en Borges antes el fascismo (2006), en la década del cuarenta, Borges elaboró un tipo de ficción y de crítica que batalló oblicuamente contra los dispositivos discursivo-ideológicos de los regímenes totalitarios, a la vez que tomó distancia del liberalismo humanista. La literatura nazi en América recoge también este aspecto y pone en primer plano precisamente esa politicidad de las ficciones de Borges, a la vez que encuentra una manera de ligar ese dispositivo antitotalitario surgido en los años cuarenta con su propia historia contemporánea, relacionando el nazismo con las más cercanas dictaduras de los años setenta.

\section{El factor nazi}

La literatura nazi en América comienza con un epígrafe de Augusto Monterroso que habla de la repetición: "Cuando el río es lento y se cuenta con una buena bicicleta o caballo sí es posible bañarse dos (y hasta tres, de acuerdo con las necesidades higiénicas de cada quien) veces en el mismo río" (LLNA: 3). Monterroso juega con el aforismo de Heráclito según el cual todo se encuentra en movimiento y, por lo tanto, es imposible la reiteración de la experiencia. Al citarlo como epígrafe, Bolaño recupera el giro lúdico y le da una segunda vuelta: si las condiciones son propicias, sugiere en su novela, la repetición no solo es posible sino incluso inevitable. La literatura nazi en América hace resonar este principio y muestra, con la historia de Ramírez Hoffman, que la broma filosófica puede convertirse en el portal de un relato sobre la repetición y el retorno de lo reprimido.

¿Qué es lo que en efecto retorna a lo largo de estas treinta vidas imaginarias, las treinta "entradas" que el libro dispone como un catálogo de "mala" literatura? A pesar de esta pretendida disposición enciclopédica, el texto nunca explicita en qué consiste concretamente el factor "nazi" de la antología. "Lo nazi" es el centro elidido, el denominador común a descubrir. El nombre de Hitler aparece esporádicamente a lo largo del libro -no más de cuatro o cinco veces- pero no es allí donde hay que buscar la conexión secreta entre los casos del catálogo, sino en ciertos indicios, recurrencias y vagos aires de familia. El lector tiene que reconstruir la trama implícita de este mapa como un crítico profesional, un descifrador o un detective. Si el policial inventó en su momento al lector investigador, La literatura nazi en América requiere uno capaz de descifrar los lenguajes, estilos y géneros de la ideología. La tarea exige complicidad y perspicacia. En algunos grupos, como el de la familia Mendiluce, el reconocimiento de las conexiones con el nazismo es más evidente porque se trama a través de nombres propios y afinidades ligadas a la historia del nacionalismo conservador (Edelmira de Mendiluce, poeta precoz, protectora de las artes, gran dama y madre de tres hijos, despliega una vasta labor filantrópica que incluye el sostenimiento de la revista El cuarto Reich argentino). En otros casos, la relación implícita con el nazismo resulta insólita, como en el desopilante grupo "Visión, ciencia-ficción", compuesto por tres escritores que no se conocen entre sí, dos norteamericanos y un guatemalteco, cuyas novelas combinan el western con el policial, la literatura bélica y la ciencia ficción en una especie de cóctel neonazi aclimatado al imaginario popular norteamericano (el caso del guatemalteco Gustavo Borda es revelador: se refugia en la idealización del heroísmo ario para compensar su propio autodesprecio racista: "A mi manera", dice Borda, "soy como una mujer en un cuerpo de hombre", 112). La pasión por el deporte, la aventura y el atletismo suelen acompañar esta literatura amante de la acción. También el gusto por los géneros épicos, desde la gauchesca hasta el western, las formas del sublime, los mitos populares y la mística. 
El imaginario exaltado y rupturista de las vanguardias se fusiona en varios casos con una fascinadora voluntad de destrucción. Figuras de "lo nuevo" (el "nuevo origen", el "nuevo hombre", el "renacer") proliferan en distintas formas, desde el arte minimalista del incomprensible -por idiota- Willy Schürlholz, hasta las expresiones más recalcitrantemente reaccionarias de las ideologías restauradoras. Como se muestra en el caso del artista brasileño Amado Couto, el programa de inventar un arte disruptivo y violento puede coincidir con el oficio de la tortura.

No hay por lo tanto un solo "sujeto nazi" ni una sola "psicología nazi" que pueda deducirse de este insólito catálogo de perfiles. "Lo nazi" es apenas un hilo que conecta vidas muy distintas que por razones también distintas contribuyen más o menos involuntariamente a urdir una malla que solo en pocos casos se conecta por relaciones personales. Lo que Bolaño explora no es tanto la continuidad ni la homogeneidad de las ideas, sino algo más difícil de asir y que se relaciona con la recurrencia y la reproducción, más o menos inconsciente, de cierto universo de sensibilidades afines. La estrategia retórica del texto, con su acumulación de casos, su imposible clasificación y su parodia de los inútiles afanes exhaustivos de la crítica, refuerza esta idea de ecos proliferantes, pero también genera, a través de ese dispositivo arborescente, una peculiar forma de suspenso. A cada instante, comenzando desde el título, se sugiere la inminencia del horror, un horror contenido por el registro paródico y que solo será liberado al final del libro, con el caso de Ramírez Hoffman. El efecto que produce esta disposición y su sorpresivo giro hacia un registro grave en el que ingresa la primera persona del narrador (cuando entra el personaje de "Bolaño" para dar el golpe de gracia que pone término a la serie), es el de un largo desencadenamiento. Una especie de pasaje al acto, en el acto final, que materializa lo que previamente se mostraba de un modo indirecto o sublimado.

En Estrella distante, ese momento de "explosión" ocupa la totalidad de la escena. ${ }^{10}$ Aquí Carlos Ramírez Hoffman recibe un nuevo nombre que acentúa su carácter alegórico: ahora se llama Carlos Wieder, apellido que en alemán significa "otra vez", "de nuevo", "nuevamente", "por segunda vez", "de vuelta” y, en algunos contextos, "una y otra vez", "la próxima vez" en frases que, según dice el texto, "apuntan al futuro" (ED: 50). Lo que retorna a través de Wieder es el furor higiénico del triunfalismo nazi. Sus "poemas aéreos" citan pasajes del libro del Génesis (Wieder escribía en el cielo con un avión a chorro de la Luftwaffe hitleriana) y al mismo tiempo cubren el firmamento con la promesa y la amenaza de un renacer chileno después de la limpieza. La acumulación de eufemismos e imágenes religiosas montadas en este espectáculo aéreo de estilo futurista, casi hacen olvidar que estas sublimidades (el cielo, el renacer, la luz, el nuevo origen) tienen como reverso la industria de la muerte. La meteórica trayectoria artística de Wieder culmina en el instante en el que él mismo parece olvidar la necesidad de sostener este registro eufemístico. Cuando expone las fotos de sus víctimas sin ningún ornato que disimule el tormento de los cuerpos, la ilusión instantáneamente se derrumba. Las fotos llegan al límite de lo aceptable en cuanto rompen el pacto implícito de glorificar los fines ocultando los medios, de tal manera que en la trayectoria "aérea" de Wieder esa exhibición de fotos marca el inicio de su inmediata caída.

Es muy significativo el hecho de que esta caída de la "estrella" chilena se produzca por un acto de sobreexposición. Wieder efectivamente expone de más, muestra lo que no debía dejarse ver. ${ }^{11}$ Las fotos se constituyen aquí en una especie de exabrupto pornográfico luego confirmado por el ingreso del poeta aéreo en la industria del snuff. ${ }^{12}$ En su exceso de entusiasmo vanguardista, Wieder parece olvidar que incluso él debe ceñirse a las pautas del decoro como norma y reparto del comportamiento social. Wieder comete una obscenidad y con ello toca simultáneamente dos extremos: llega al límite de lo tolerable para el régimen estético (un régimen aparentemente capaz de aceptarlo todo siempre que se mantenga dentro de los límites del arte) y de lo aceptable para el propio régimen estatal. Al exponer la cara concretamente material de la alianza entre el arte y el poder, Wieder atenta contra su propio lugar de artista al servicio del Estado. Si algo afirman los cuerpos expuestos por Wieder en el colmo de su cinismo, es que ellos no son lenguaje, ni arte, ni simples fantasmagorías. Esos cuerpos no son imagen de algo más, ni pueden reducirse a ningún simbolismo,

10 "Espejo y explosión" son las palabras con las que se describe el caso de Ramírez Hoffman en relación con las historias previas en la nota introductoria de Estrella distante: "El último capítulo de La literatura nazi servía como contrapunto, acaso como anticlímax del grotesco literario que lo precedía, y Arturo deseaba una historia más larga, no espejo ni explosión de otras historias sino espejo y explosión en sí misma" (ED: 11). De acuerdo con esto, Estrella distante busca ser un espejo y explosión "en sí”, pero ¿ante quién? La nota interpela al lector, quien debe reconocer los reflejos de ese espejo que ofrece la novela.

${ }^{11}$ Escribe Carmen Perrilli: "El cuarto lleno de imágenes muestra lo obsceno, lo que sobrepasa los límites del espectáculo aceptable y debería haber permanecido fuera de escena. La estética superrealista de las fotos documenta lo imposible; habla de aquello que se esconde y lo hace de manera magistral [...] Wieder se excede aun ante el régimen" (2014: 145).

${ }^{12}$ El contenido de las fotografías es omitido en La literatura nazi en América, en tanto que Estrella distante sí desarrolla una descripción de la apuesta estética de Wieder. Para un análisis de este de este pasaje y de la función de la fotografía como "forma del horror", véase Carlos Walker (2014). 
simplemente no se pueden reducir, tout court.

De manera que la salida a la luz de los restos no solo marca el fin de la estrella de Wieder, sino también de cualquier ilusión sobre la inocencia del arte. La historia del artista criminal es, en efecto, como dice la nota introductoria de la novela, una "explosión" de posibilidades latentes y un "espejo" ante el que se hace comparecer al mundo literario (tanto a escritores como a lectores, críticos, fans, patrocinadores, etcétera). ${ }^{13}$ Al ser un espejo y no una ventana, lo que muestra este relato no es la otredad de la maldad, sino su inscripción en el propio rostro, su aberrante familiaridad. El perfil siniestro -en el sentido freudiano: unheimlich- de Wieder, ${ }^{14}$ no solo pasa por sus ojos impersonales o su aspecto indefiniblemente inhumano, sino por el hecho de que produce un desvío criminal en el uso de los dispositivos simbólicos. Un desvío que, sin embargo, revela algo crucial sobre el poder de la cultura y sus ficciones.

\section{Espejo del mal}

Los críticos no suelen incluir entre los textos de Borges con los que dialogan estas novelas de Bolaño, el cuento más explícito sobre el nazismo: "Deustches Requiem". ${ }^{15}$ Este cuento fue publicado en Sur en 1946 y posteriormente incorporado al volumen El Aleph (1949). ${ }^{16}$ En él, Borges hace hablar a un torturador alemán que pronuncia o redacta un alegato de defensa del nazismo durante la noche previa a su ejecución. Salvo por las notas al pie escritas por un imaginario editor, todo el texto surge de la voz de este personaje. El criminal, Otto Dietrich Zur Linde, se presenta como un vástago de la Alemania guerrera, pero también como un hijo de la nación artística y filosófica, incluso como un hombre de fe:

Nací en Marienburg, en 1908. Dos pasiones, ahora casi olvidadas, me permitieron afrontar con valor y aun con felicidad muchos años infaustos: la música y la metafísica. No puedo mencionar a todos mis bienhechores, pero hay dos nombres que no me resigno a omitir: el de Brahms y el de Schopenhauer. También frecuenté la poesía; a esos nombres quiero juntar otro vasto nombre germánico, William Shakespeare. Antes, la teología me interesó, pero de esa fantástica disciplina (y de la fe cristiana), me desvió para siempre Schopenhauer, con razones directas; Shakespeare y Brahms, con la infinita variedad de su mundo. Sepa quien se detiene maravillado, trémulo de ternura y de gratitud, ante cualquier lugar de la obra de esos felices, que yo también me detuve ahí, yo, el abominable. (DR: 576-577)

Nadie podría suponer que Borges pretendía con esto matizar los crímenes del nazismo. Su antifascismo era manifiesto y el cuento fue además publicado en la revista Sur, cuya oposición al nazismo era bien conocida. Sin embargo, la elección de esta perspectiva resultaba cuando menos turbadora en un momento en el que se deseaba ante todo escuchar el testimonio de las víctimas (Louis 2006). ${ }^{17}$ Mientras que la prensa difundía las noticias del genocidio y hacía la crónica detallada de los juicios de Nuremberg, Borges inventaba en este cuento un alegato nazi. "No pretendo ser perdonado, porque no hay culpa en mí, pero quiero ser comprendido" (1989: 576). La confesión de Otto Dietrich Zur Linde no supone ningún arrepentimiento ni

\footnotetext{
${ }^{13}$ Como decía un personaje de El espíritu de la ciencia-ficción (1984), "la Maldad antes de estrenarse ensaya sus piruetas en pequeñito" (2016: 168). Bolaño ensayó distintas maneras de elaborar la temática del nazismo antes de publicar La literatura nazi en América y Estrella distante. En El espíritu de la ciencia-ficción, una novela escrita en 1984 e inédita hasta 2016, incorporó ciertos elementos del imaginario belicista de la Segunda Guerra Mundial y los combinó con imágenes del militarismo chileno, mediante el recurso de interpolar en la novela algunos fragmentos de otra novela escrita por uno de los personajes. Unos años después, regresó al tema del nazismo en un relato escrito en 1989 e inédito hasta 2010, El tercer Reich, una novela en la que nuevamente buscó producir un efecto de extrañamiento, en este caso yuxtaponiendo en órdenes paralelos la descripción de las tácticas del juego de guerra (aquí un juego de guerra en el que ganaría el nazismo) y el relato lineal de una intriga amorosa que gira progresivamente hacia el género policial. Estas dos novelas, que hoy se leen como textos terminados, no fueron publicadas en su momento sino conservadas inéditas, al igual que Sepulcro de vaqueros, una compilación de relatos desconocidos o versiones previas de otros publicados posteriormente por Bolaño, tales como el del avión alemán que traza inscripciones fascistas sobre el cielo de Chile, que luego aparece en la historia de Ramírez Hoffman.

14 “La categoría de 'lo siniestro' (Das Unheimliche) teorizada por Freud a partir de los cuentos de Hoffmann trabaja sobre la idea de que lo siniestro es todo lo que debería haber quedado oculto, secreto, pero que se ha manifestado. En otra inflexión de esta cuestión recordemos que el más infame de los personajes de Bolaño, se llama Ramírez Hoffman" (Manzoni 2003: 27). Vale recordar que Freud elaboró su teoría de "lo siniestro" a través del comentario del cuento "El hombre de arena" de E.T.A. Hoffmann.

${ }^{15} \mathrm{DR}$ en las citas a continuación

16 “Deutsches Requiem” fue publicado por primera vez en Sur 15 (136), 2/1946, pp. 7-14. Luego se incorporó a El Aleph (1949).

17 Sobre la amplia cobertura periodística de los juicios en La Nación, véase Louis 2006: 356-361.
} 
apela a la compasión. Lo que busca es el reconocimiento de una cierta racionalidad, incluso de una cierta familiaridad con sus razones. Su discurso pretende mostrar la legitimidad de esas razones recurriendo a tópicos mesiánicos tales como la idea de fundar un tiempo nuevo, de lograr un despertar mundial o una nueva aurora. "Había en el aire que respirábamos un sentimiento parecido al amor", dice en el colmo de su idealismo (DR: 579). Todo indica que Borges busca enfatizar la violencia solapada de ese idealismo, al poner en boca del criminal una retórica saturada de imágenes sublimes que contrastan bruscamente con los testimonios salidos a la luz tras el fin de la guerra. Los crímenes no están representados en la ficción (solo aludidos), sin embargo forman parte de ella en tanto da lugar al contraste entre el "amor" del nazi y los horrores del nazismo, contraste en el que se basa buena parte de la eficacia de este texto.

Se podría decir entonces que "Deustches Requiem" plantea ciertos interrogantes relacionados con ese choque entre las razones (idealistas) y las consecuencias (criminales). El problema, en última instancia, es ético y político, pero, como advirtió Louis (2006), Borges no recurre a la fábula moral para plantear una posición crítica frente al nazismo, sino que apela a un tipo de ficción que opera indirectamente, sin emitir juicios condenatorios ni reforzar las complicidades con el lector. ${ }^{18}$ En este caso, la postura crítica surge al poner de manifiesto los aspectos inquietantes del discurso criminal, no solo por lo que éste tiene de inasimilable, sino sobre todo por lo que tiene de parecido con el discurso del lector. El foco de este discurso, que evidentemente hay que leer con la distancia irónica que le impone el marco ficcional, está colocado en la violencia mesiánica. Zur Linde se considera a sí mismo un hombre moral, se ve como un instrumento de la Historia, entendida por él como una razón absoluta e infalible. Es por eso que no puede admitir ninguna culpa, ya que la causa de todas sus acciones queda delegada en ese principio trascendente que en su discurso ocupa el lugar de Dios. En este sentido, su alegato plantea un argumento hasta cierto punto previsible para la mirada crítica liberal, de acuerdo con el cual el individuo no es sino el medio por el que se realiza la Historia. Sin embargo, la fuerza del texto no reside simplemente ahí, sino en el sistema de reflejos que establece entre la víctima y el victimario. La mayor prueba de fidelidad de Zur Linde al imperativo absoluto de la Historia, no consiste en someter a otro ser humano, sino en someterse a sí mismo en su propia humanidad compasiva, al tener que encarcelar a su admirado poeta David Jerusalem. "Ignoro si Jerusalem comprendió que si yo lo destruí, fue para destruir mi piedad", dice en su defensa (DR: 579). Como en la historia bíblica de Isaac, el sacrificio de uno es aquí también el sacrificio del otro. El texto busca subrayar esta paradójica identificación de los destinos sacrificiales, insinuando la convergencia de los imperativos seculares del nazismo con el Dios judeocristiano. El mayor indicio de esta convergencia se encuentra en el epígrafe bíblico que encabeza el cuento, el versículo de Job 13: 15: "Aunque Él me quitare la vida, en Él confiaré". El impacto de la cita no solo surge del hecho de que apela al libro sagrado del judaísmo para introducir un discurso cuyo trasfondo es la masacre antisemita, sino que se la usa para justificar las razones del propio genocida. La cita de Job resume la máxima a la que zur Linde consagra su acción en los campos de exterminio: la escritura de la Historia (como la de Dios) es infalible y no se cuestiona ("en Él confiaré"). ${ }^{19}$ La doble aplicación del versículo muestra la identidad posible entre la víctima y el victimario, reunidos ambos por un principio común, y con ello introduce no solo un impensado aire de familia entre el nazi y el judío, sino también entre el nazi y el lector, en tanto este lector argentino también proviene de la tradición judeocristiana. Si algo revela este cuento en nada complaciente, es justamente que el arte y la cultura no son el reservorio garantizado de los valores de la paz. El nazi no es un bárbaro ni un enemigo del pensamiento, como repetía el discurso humanista, sino un sujeto moral y culto.

De hecho, lo primero que el texto pone en evidencia son su cultura y racionalidad. Resulta notable que la voz de zur Linde no solo haga resonar indistintamente ciertos tópicos del nazismo y la literatura bíblica, sino que los enhebre con la propia retórica borgeana, de modo tal que en el alegato se pueden reconocer al mismo tiempo la voz del criminal y la de Borges. El tono, los giros aforísticos, ciertas imágenes de cuño borgeano (como el trazado de una genealogía familiar doblemente militar y letrada, o la presencia del gran gato que

\footnotetext{
18 “Así, podría decirse que, en la perspectiva borgesiana, narrar el horror de los campos no debería significar adoptar una estética que dicta a los lectores sus sentimientos, que les indica a quien admirar, a quien despreciar, a quien condenar y con quien hay que simpatizar. Este tipo de estrategia se apoya en una moral externa al texto, para reforzar nuestra moral, razón por la cual Borges la combate. Adoptar este tipo de estrategia conduciría a una literatura realista. Por lo tanto, podemos concluir que una de las razones por las que Borges elige escribir la ficción del discurso de un verdugo reside en la posibilidad de explorar lo que podía llamarse 'el juicio autónomo del texto', es decir su capacidad para generar una estética que no se defina con relación a una moral externa al texto, a nuestra moral como sujetos sociales" (Louis 2006: 296).

${ }^{19}$ En el clímax de su alegato, zur Linde exalta su paradójico triunfo: "Se cierne ahora sobre el mundo una época implacable. Nosotros la forjamos, nosotros que ya somos su víctima. ¿Qué importa que Inglaterra sea el martillo y nosotros el yunque? Lo importante es que rija la violencia, no las serviles timideces cristianas", dice el criminal, anunciando un futuro de conflagración (1989: 580-581).
} 
prefigura lo inevitable, al igual que en el relato "El Sur", o sentencias que vuelve a trabajar en otros textos, del tipo "la desventura requiere paraísos perdidos" o "todos los hombres nacen aristotélicos o platónicos") son puestos en boca del torturador poniendo a prueba el límite de la autoría o la distinción de los dominios discursivos. Si no hay un lenguaje propio del criminal, un lenguaje en sí abominable, ¿qué distinguiría entonces el discurso del genocida de la "buena" literatura?

En "Deustches Requiem", Borges inventa un personaje cuya racionalidad resulta tanto más ominosa cuanto más aberrante es el contraste con el contexto de enunciación. La realidad de las muertes estaba a la vista del público en 1946. Borges sin embargo evita referirse a ellas y las sustituye por otro tipo de horror que surge del discurso mismo. Ese horror proviene del enrarecimiento de las palabras puestas en boca del criminal, de la desviación que sufren los textos al constituirse en justificativos de la destrucción y de la familiaridad de esos textos para el lector. Las mismas citas, los mismos lugares comunes que pueden integrar un discurso antifascista, dan forma a una moral totalitaria. El texto parece hacer una advertencia sobre los peligros de esa deriva.

La conexión con las novelas de Bolaño y particularmente con el personaje de Ramírez Hoffman/Wieder, resulta clara cuando se considera la función amenazadora de los versos aéreos y el uso de referencias bíblicas como preámbulo de los actos criminales. Trastocadas y confusas, las alusiones a un tiempo de consumación, un tiempo propicio o kairos, son mensajes de advertencia dirigidos a la incauta población chilena, y fuera de la ficción, a los lectores capaces de advertir su sentido ominoso. "DIXITQUE ADAM HOC NUNC OS EX OSSIBUS MEIS ET CARO DE CARNE MEA HAEC VOCABITUR VIRAGO QUONIAM DE VIRO SUMPTA EST" (ED: 186; "Y dijo Adam: Esto es ahora hueso de mis huesos, y carne de mi carne: ésta será llamada Varona, porque del varón fue tomada", Gen. 2, 23) dicen los versículos aéreos de Ramírez Hoffman, con el mismo entusiasmo con que el nazi de Borges se refiere a la creación del hombre nuevo: "El nazismo, intrínsecamente, es un hecho moral, un despojarse del viejo hombre, que está viciado, para vestir el nuevo" (DR: 578). Ese renacer exige una gran conflagración, una lección moral a gran escala. "APRENDAN DEL FUEGO", remata el mensaje de Ramírez Hoffman (LLNA: 186). Estrella distante cambia algunos versículos, pero la advertencia es la misma: "ET VIDIT DEUS... LUCEM QUOD... ESSET BONA... ET DIVISIT... LUCEM A TENEBRIS", escribe el avión, aludiendo al nuevo génesis de la humanidad (ED: 39; "Y vio Dios que la luz era buena: y apartó Dios la luz de las tinieblas", Gen. 1, 4). "APRENDAN", dice para coronar el acto la última sentencia inscripta sobre la capital de Chile (ED: 39).

Aquí ya no es el torturador, sino el artista el que funde el texto religioso con la acción militar. La creación es un arte, y el creador un artista. El horror nuevamente reside en esa perturbadora promiscuidad de lenguajes, y en el deslizamiento, casi imperceptible para los testigos de la escena, de la acción poética a la de exterminio. ${ }^{20}$

\section{El Borges de Bolaño}

No parece casual que estos aspectos de la obra de Borges -su orientación metaficcional, su distanciamiento crítico, su predilección por las paradojas y los equívocos, su desconfianza de los discursos totalizadores, su manera de conectar la teología con la ideología y la política- fueran redescubiertos y revalorizados por la crítica justamente a finales del siglo XX, en el contexto del posmodernismo, la caída del comunismo, el final de la Guerra Fría y la nueva defensa mundial de las democracias. También Bolaño escribió sus novelas desde un contexto conscientemente finisecular, que en su caso adoptó un tono predominantemente melancólico. En sus obras, el siglo suele aparecer como un campo de batalla sembrado de cadáveres o como una larga pesadilla de la que no se termina de despertar. Así como otros críticos vieron en Borges a una especie de profeta de los tiempos posmodernos, también él exaltó su obra por la lucidez de sus fícciones y consideró que contenía una clave para el presente, pero juzgó que ese presente se encontraba en decadencia y que

\footnotetext{
${ }^{20}$ Gonzalo Aguilar encuentra en la figura de la "literatura nazi" también una crítica solapada al autoritarismo intelectual de la izquierda: "Uno de los efectos más perturbadores de estos cruces es la sombra siniestra que proyecta, en estas novelas, la literatura realmente existente: en La literatura nazi en América, por ejemplo, los escritores, fascistas estudian a los poetas comunistas Pablo Neruda y Pablo de Rokha, porque lo único que hay que hacer, para lograr el modelo de literatura panfletaria, es tomar sus poemas y poner a Mussolini en vez de Stalin y Stalin en vez de Trotski y 'reajustar ligeramente los adjetivos'. En este pequeño desliz, en este mínimo cambio de palabras, la inexistente literatura nazi en América en una sombra, en un doble frágil y siniestro de la literatura en América (y, extensivamente, de su cultura). Aquello que se le opone pero que, en ciertas condiciones, lo duplica, lo refleja, lo repite" (2003: 149).
} 
Borges era una lección que la literatura debía volver a escuchar. El Borges de Bolaño, en suma, tiene al mismo tiempo la potencia crítica de la filosofía del fin de siglo, pero también un elemento heroico de esa modernidad dejada atrás que Bolaño miraba con nostalgia. En "El bibliotecario valiente", un retrato de Borges escrito con tono apologético, Bolaño reúne esos dos elementos que parecen constituir el perfil ideal del escritor: la orientación bibliófila y la dosis necesaria de intransigencia para una literatura que no se rinde más que a sí misma. Si bien el texto no explicita a qué responde exactamente esa valentía del bibliotecario, cabe deducir que se relaciona con ese rigor y en alguna medida también con la filiación anarquista de Borges, que coincide con la propia experiencia de Bolaño y con su resistencia a las instituciones y formaciones orientadas al poder, incluso cuando se definen revolucionarias.

No hace falta aclarar que en esta imagen de Borges se desarticula aquella vieja dialéctica del arte y la vida que contraponía al escritor "bibliotecario" ("intelectual", "cerebral" o "puro") a cualquier otro que reflejara alguna forma de vitalismo (un ejemplo de esta lectura es Ernesto Sábato en "Los dos Borges"). Bolaño deliberadamente conjuga los dos aspectos en la imagen de Borges, y no solo en él, sino también en su imagen propia (Andrews 2014). La reunión de arte y vida, poesía y acción, se conjuga en la ficción a través de su alter ego. Dentro La literatura nazi en América, se reconoce a través del personaje de "Bolaño", que ingresa en la ficción no solo para contar la historia de Ramírez Hoffman, sino para hacer justicia poética y poner fin al "juego" literario que hasta ese momento venía dándose. Es aquí justamente cuando el texto muestra su trama novelística y da respuesta a los dilemas y paradojas que en las historias anteriores se planteaban por medio de la parodia y el humor. Esa respuesta implica un acto de justicia que el relato deja en manos del narrador, o mejor dicho: en manos de la asociación final del narrador con Abel Romero, el poeta y el detective. Es decir que esa respuesta implica en definitiva el reconocimiento de que las formas literarias no son inocentes ni ajenas a las atrocidades de la historia, y que la lucidez a la que exhorta el complejo dispositivo ficcional de este libro es quizás la única salida al mal de la repetición.

Con "Bolaño", convertido en "Belano" a partir de Estrella distante, ingresa en esta narrativa un tipo de héroe particular, a la vez literario y curtido por la historia, bibliómano y "golpeado" (beaten: beatnik), con rasgos de hippie, cowboy, rocker, gaucho, renegado o "detective salvaje". Nada podría parecer más alejado de Borges que este conjunto de figuras nostálgicas rejuvenecidas en la ficción. Sin embargo, algo sucede en esta ficción para que la combinación sea posible y se logren recuperar, al mismo tiempo, algunos de los más característicos procedimientos borgeanos junto con un tipo de heroísmo que adscribe a la juventud infrarrealista de Bolaño y a ciertos íconos de los años setenta. Josefina Ludmer advertía en 1999 que Borges se había vuelvo canónico y que por lo tanto era necesario "salir de Borges" pero sin olvidarlo, "desde adentro de Borges" (2000). Esto es lo que efectivamente podemos ver en estas novelas de Bolaño, una apropiación que lo reinventa, y sobre todo una repolitización de la obra borgeana que lo vuelve a leer desde una faceta poco explorada: la de un antifascismo que, a finales del siglo XX, se tornó más claramente legible de lo que había podido ser en su momento.

\section{Referencias bibliográficas}

Aguilar, Gonzalo (2002), "Roberto Bolaño, entre la historia y la melancolía”, en Celina Manzoni (ed.). Roberto Bolaño: la escritura como tauromaquia. Buenos Aires: Corregidor, pp.145-152.

Aguilar, Paula (2015). Libros de arena, desiertos de horror. Literatura y memoria en la narrativa de Roberto Bolaño. Buenos Aires: Corregidor.

Andrews, Chris (2014). Roberto Bolaño's Fiction: an Expanding Universe. Columbia University Press, 2014.

Bolaño, Roberto (1996). La literatura nazi en América. Barcelona: Seix Barral.

Bolaño, Roberto (1996). Estrella distante. Barcelona: Anagrama, 1996.

Bolaño, Roberto (2011), "Los mitos de Cthulhu”, en El gaucho insufrible. Barcelona: Anagrama, pp. 159-177.

Bolaño, Roberto (2013a), "Derivas de la pesada", en Entre paréntesis. Barcelona: Anagrama, pp. 23-30.

Bolaño, Roberto (2013b), "El bibliotecario valiente”, en Entre paréntesis. Barcelona: Anagrama, pp. 289-291.

Bolaño, Roberto (2013c), "Ese extraño señor Pauls", en Entre paréntesis. Barcelona: Anagrama, pp. 207-208.

Bolaño, Roberto (2016). El espíritu de la ciencia-ficción. Barcelona: Anagrama.

Borges, Jorge Luis (1989). “Deustches Requiem”, en Obras completas. Tomo I. Buenos Aires: Emecé, pp. 576-581.

Cuesta Abad, José Manuel (1995). Ficciones en crisis: poética e interpretación en Borges. Madrid: Gredos.

Crusat, Cristian (2014), "Humorístico oprobio: el destino irónico de las 'vidas imaginarias' de Jorge Luis Borges, Juan Rodolfo Wilcock, y Roberto Bolaño", Hispanic Research Journal, 17 (6) (2014), pp. 504-52.

Cusset, Françoise (2005). French Theory. Foucault, Derrida, Deleuze \& Cía. y las mutaciones de la vida intelectual en Estados Unidos. Barcelona: Melusina.

Doll, Ramón (1999), "Discusiones con Borges”, en Martín Lafforge (comp.). Antiborges. Buenos Aires: Javier Vergara Editor, pp. 31-41.

Louis, Annick (2007). Borges ante el fascismo. Bern: Peter Lang. 
Ludmer, Josefina (2000), “Cómo salir de Borges", en William Rowe, Claudio Canaparo y Annick Louis (comps.). Jorge Luis Borges: intervenciones sobre pensamiento y literatura. Buenos Aires: Paidós, pp. 289-300.

Manzoni, Celina (2002), "Biografías mínimas/ínfimas y el equívoco del mal", en Celina Manzoni (ed.). Roberto Bolaño: la escritura como tauromaquia. Buenos Aires: Corregidor, pp. 17-32.

Manzoni, Celina (2002), "Narrar lo inefable. El juego del doble y los desplazamientos en Estrella distante", en Celina Manzoni (ed.). Roberto Bolaño: la escritura como tauromaquia. Buenos Aires: Corregidor, pp. 39-50.

Pauls, Alan (2015). "Borges y Bolaño, una conversación” (conferencia).

Disponible en: http://flacso.org.ar/producciones/borges-y-bolano-una-conversacion-por-alan-pauls/

Pauls, Alan y Nicolás Helft (2000). El factor Borges. Nueve ensayos ilustrados. Buenos Aires: Fondo de Cultura Económica.

Perrilli, Carmen (2014), "Cómo construir un escritor infame: Roberto Bolaño", en Sombras de autor. La narrativa latinoamericana entre siglos (1990-2010), pp. 137-148.

Sábato, Ernesto (1996), "Los dos Borges" [El escritor y sus fantasmas, 1963], en Obra completa. Ensayos. Buenos Aires: Seix Barral, pp. 303-311.

Walker, Carlos (2013), "Horror y colección en Roberto Bolaño", Kamchatka, 1 (2013), pp. 155-177.

Walker, Carlos (2016), "La reflexión visual en Roberto Bolaño. Narración, dictadura y vanguardias en Estrella distante", Ciencia política, 11 (22) (2016), pp. 189-212. 